An Undergraduate Positive Psychology Course as Prevention and Outreach

G. Tyler Lefevor, ${ }^{1}$ Dallas R. Jensen, ${ }^{2}$ Payton J. Jones, ${ }^{2}$ Rebecca A. Janis, ${ }^{3}$ \& Chih Han Hsieh ${ }^{2}$

${ }^{1}$ Rhodes College, ${ }^{2}$ Brigham Young University, ${ }^{3}$ Penn State University

Corresponding Author:

G. Tyler Lefevor, Ph.D.

Department of Psychology

Rhodes College

2000 N. Parkway

Memphis, TN 38112

Phone: 801-573-4370

E-mail: lefevort@rhodes.edu

Acknowledgments: we would like to gratefully acknowledge the support of a research grant from Brigham Young University's Counseling and Psychological Services. 


\begin{abstract}
College counseling centers nationwide are having difficulty meeting the increasing demand for services they are seeing. We present an undergraduate positive psychology course taught as outreach and prevention by counseling center therapists as a way to potentially address this demand. During the two primary semesters of the 2012-2013 and 2013-2014 academic years, 133 students enrolled in the course and completed pre and post measures. Students evidenced significantly decreased psychological distress, increased psychological well-being, and increased subjective happiness. We discuss the format of this course and its elements as both outreach/prevention and therapeutic interventions to meet the increased demand for services.
\end{abstract}

Keywords: outreach; prevention; positive psychology; teaching; collegiate mental health 


\section{An Undergraduate Positive Psychology Course as Prevention and Outreach}

Emerging adulthood is a period of rapidly shifting roles and demands during which many begin to experience psychological distress and long-term emotional maladjustment (Pittman \& Richmond, 2008; Gall, Evans, \& Bellerose, 2000; Samuolis \& Griffin, 2014). Almost half of all college students have a diagnosable psychiatric disorder (Blanco et al., 2008), and it appears that the rate of mental illness among college students is steadily increasing (Hunt \& Eisenberg, 2010). Even at subclinical levels, symptoms of psychological distress can cause significant impairment in daily life and have been linked to poor academic outcomes including student attrition (Judd, Akiskal \& Paulus, 1997; Milem \& Berger, 1997). Further, an increasing number of students are seeking mental health services at college counseling centers (Center for Collegiate Mental Health [CCMH], 2015), leading many centers to look for alternative ways to meet a rising demand for services.

Many centers have turned to expanding their outreach and prevention efforts as a way to curb the increased demand for services (Hunt \& Eisenberg, 2010). Positive psychology may be ideally situated to inform counseling centers' prevention, outreach, and therapeutic work with emerging adults. A wide range of positive psychology interventions have been shown to be effective in the improvement of well-being and reduction of symptoms of depression in student populations (Seligman, Schulman, DeRubeis, \& Hollon, 1999; Seligman, Schulman, \& Tryon, 2007; Seligman, Rashid, \& Parks, 2006; Parks \& Szantzo, 2013). Hurley and Kwan (2012) found that savoring was negatively correlated with depressive symptoms in college students, and Klibert and colleagues (2014) found that the character strength of resilience moderated the relationship between perfectionistic expectations among college students and prevalence of depression. Increases in well-being are also synergistic with increases in student learning 
(Seligman et al., 2009). These effects may be at least partially attributed to the broadening of attention that results from increased well-being (Rowe, Hirsh, \& Anderson, 2007). It is probable that utilizing positive psychology interventions and teaching college students distress management may prove an effective mechanism to buffer psychological problems in college students and increase academic success.

\section{Positive Psychology Interventions}

Many of the principles of positive psychology have been translated into concrete interventions that may be used by primary clinicians and outreach efforts. The format of these positive psychology interventions (PPIs) varies, ranging from online interventions (Boehm, Lyubomirsky, \& Sheldon, 2011; Ouweneel, Le Blanc, \& Schaufeli, 2013), to self-help books (Parks \& Szanto, 2013) to individual and group therapy (Seligman et al., 2006; Abedi \& Vostanis, 2010). PPIs typically have the intention of improving overall well-being and seek to do so by focusing on improving a specific strength or value such as gratitude (Emmons \& McCullough, 2003), mindfulness (Grossman, Niemann, Schmidt, \& Walach, 2004), forgiveness (Reed \& Enright, 2006), or resilience (Abbott, Klein, Hamilton, \& Rosenthal, 2009). PPIs have largely been found to be efficacious (Bolier et al., 2013; Sin \& Lyubomirsky, 2009) and effective (Hone, Jarden, \& Schofield, 2015). PPIs appear to be beneficial for both the promotion of specific strengths as well as for general improvement in well-being and reduction in depressive symptoms (Bolier et al., 2013).

While targeted PPIs have been effective and may be incorporated eclectically into therapy, there is evidence that a multifaceted approach that targets several areas of functioning may be preferable when it comes to enhancing well-being and reducing distress (Fordyce, 1977, 1983; Sin \& Lyubomirsky, 2009). This type of approach involves using a mixture of several 
interventions that target improvement in different areas, with the overall goal to increase wellbeing. Multifaceted approaches can also impact specific strengths, such as gratitude (Huynh, Hall, Hurst, \& Bikos, 2015) and mindfulness (Feicht et al., 2013). A multifaceted approach necessarily involves several points of contact and may consequently be best implemented either as a workshop series or elective course taught by counseling center staff.

\section{The Teaching of Positive Psychology Courses}

As positive psychology has come to the forefront of psychology, a number of universities have begun to offer courses in positive psychology (Linley, Joseph, Harrington, \& Wood, 2006). Biswas-Diener and Patterson (2011) propose an experiential framework for the teaching of positive psychology that invites teachers to instruct students on the effects of various interventions and then assign students to complete those interventions in their own lives, arguing that such an approach maximizes both the potential impact on students and the degree of content learning that takes place as a result. This experiential, transformative approach has been taken by others with great success (Russo-Netzer \& Ben-Shahar, 2011).

Despite general support for a transformative approach to teaching positive psychology, studies evaluating the psychological impacts of these courses are scarce. Currently, there are two empirical articles that provide some support for the efficacy of positive psychology courses in increasing well-being (Goodmon, Middleditch, Childs, \& Pietrasiuk, 2016; Maybury, 2012). However, both of these investigations were limited by relatively small samples $(n=38$ and 23 respectively) and neither course appeared to be an effort at outreach/prevention made by a counseling center. Consequently, neither study was able to calibrate the results by the average amount of growth seen in psychotherapy. 
Our investigation expands upon Maybury (2012) and Goodmon et al. (2016) by greatly increasing the sample size $(\mathrm{n}=133)$, using more complex statistical methodology (MANOVA as opposed to a paired-sample t-test), and by measuring the effects of positive psychology course instruction in four different courses over 2 years. In addition, the present course was taught as an outreach and prevention effort by therapists and was explicitly focused on improving student well-being, which may make the results more likely to be generalizable to other centers.

\section{Overview of the Course: an Experiential Outcome-Focused Framework}

The present study is an evaluation of an experiential undergraduate positive psychology course taught through the counseling center, The Science and Practice of Positive Living (SPOPL). The course was created as an elective 2-credit course for undergraduates in a university in the Mountain West region of the United States, and was designed in line with the counseling center's mission to improve student mental health. The course followed the experiential approach described in Biswas-Diener \& Patterson (2011), emphasizing the application of positive psychology in the students' own lives over content memorization. Therefore, the primary goal of this course was to help students apply positive psychology interventions in their own lives to increase well-being, decrease psychological distress, and learn through experience such that students would experience less need to seek psychological services.

The SPOPL course followed a multifaceted approach, utilizing a wide variety of interventions, as initially recommended by Fordyce (1977), and validated through meta-analysis by Sin and Lyubomirsky (2009). Each week, the course focused on a specific value, character strength, or ability, with class time divided between lecture, small group discussion, and student presentations. Throughout the semester, each student was assigned to find and present media materials (i.e., videos, articles, etc.) that exemplified principles covered in class, following 
recommendations from the literature (e.g., Jayawickreme \& Forgeard, 2011; Russo-Netzer \& Ben-Shahar, 2011). In addition to in-class meetings, students were assigned a specific positive psychology intervention to complete each week, relating to the weekly focus. The topics covered in the course in order of presentation were general happiness, interpersonal relationships, gratitude, character strengths, distress management, purposes and values, decision making, mindfulness, savoring, and flow. Overall, the course was designed to apply positive psychology interventions in the classroom as an effective way to increase student learning. An overview of the course and its assignments is provided in Table 2. The authors are happy to share additional information or course materials with any interested parties.

\section{Hypotheses}

We predicted that after completing the course, students would exhibit increased wellbeing and decreased ill-being. We hypothesized that 1) students would exhibit the most significant improvement in measures more centrally related to class material. Specifically we hypothesized that students would exhibit 1a) improved psychological well-being, 1b) increased subjective happiness, and 1c) decreased psychological distress. We also hypothesized that 2) students would exhibit mild improvement in topics covered in a single unit. Specifically, we hypothesized that students would exhibit 2a) increased optimism, 2b) increased academic selfefficacy, 2c) increased approaches to happiness, 2d) increased gratitude, 2e) increased mindfulness, and 2f) increased savoring.

Methods

\section{Participants}

We recruited 146 students at a private university in the mountain west United States to participate in exchange for two $\$ 10$ gift cards. Participants were recruited from the Science and 
Practice of Positive Living Course during the primary two semesters of the 2012-2013 and 20132014 academic years. Participants completed "pre" measures during the first two weeks of the course, prior to the introduction of the first module of the course. Participants completed "post" measures by the last day of the course, which was before final examinations. Thirteen participants failed to fill out follow-up measures and were excluded from subsequent analyses, leaving a final sample of 133 participants. Participants failing to complete the study did not differ significantly from participants who completed the study on demographic or outcome variables.

The sample was $69 \%$ female with a mean age of $21.14(S D=2.35)$ ranging from $17-33$. Ethnically, participants identified as Caucasian (88.7\%), Hispanic (3.0\%), Asian (2.3\%), African American (1.5\%), multi-ethnic (2.3\%), Native American (0.8\%), Pacific Islander (0.8\%), and other $(0.8 \%)$. Participants reported being at various stages in their academic development including first year (15.8\%), sophomore (18.8\%), junior (31.6\%), senior $(32.3 \%)$, and graduate student $(0.8 \%)$ with one student reporting an "other" academic status. Students were primarily single $(80.5 \%)$ though a substantial proportion was married $(19.5 \%)$.

\section{Procedure}

Participants were instructed that their participation in the study was voluntary and would not affect their grade in the course. They were instructed that their responses would be kept confidential and would be used to assess the impact of the course on their psychological health and well-being. Study participants required approximates 45-60 minutes per session to complete the study's instruments.

\section{Instrumentation}

Psychological Well-Being. Well-being was measured using Ryff's scales of Psychological Well-Being (Ryff, 1995; Ryff \& Keyes, 1995). This is an 84-item scale with 6 
dimensions with 14-items per dimension: autonomy, positive relations with others, purpose in life, self-acceptance, environmental mastery, and personal growth with good internal consistency (subscale alphas ranging from .85 - .91). Items are rated on a 6-point likert scale with "strongly disagree" and "strongly agree" as anchors. Sample items include "Most people see me as loving and affectionate" and "I like most aspects of my personality."

Life Orientation Test-Revised. Optimism was measured using the Life Orientation TestRevised (Scheier, Carver, \& Bridges, 1994). This is a 10-item scale measured on a 5-point likert scale from "strongly agree" to strongly disagree" with good internal consistency $(\alpha=.78)$. Sample items include "In uncertain times, I usually expect the best" and "I hardly ever expect things to go my way" (reverse scored).

Outcome Questionnaire. Psychological distress was measured using the Outcome Questionnaire-45 (Lambert et al., 1996). This is a 45-item scale with 3 subscales with 15 items each with acceptable to excellent internal consistencies (alphas ranging from .70 - .92). The subscales are symptom distress (e.g., "I have difficulty concentrating"), interpersonal (e.g., "I am satisfied with my relationships with others"), and social role (e.g., "I feel that I am doing well at work/school"). Each item was rated on a 5-point Likert scale ranging from "never" to "almost always."

Self in School. Academic self-efficacy was measured using the Self in School measure (Smith, 1988). This measure is a 15-item scale measured on a 7-point likert scale from "completely false" to "completely true" with excellent internal consistency $(\alpha=.91)$. Sample items include "I have the ability to do well in my school work" and "I am a good student." Approaches to Happiness Scale. Different approaches to happiness were measured using the Orientations to Happiness Scale (Peterson, Park, \& Seligman, 2005). This is an 18-item scale 
with 3 subscales, with acceptable to good internal consistency (alphas ranging from .77 - .88). Each subscale consists of 6-items. Subscales include a life of meaning (e.g., "My life serves a higher purpose"), a life of pleasure (e.g., "For me, the good life is the pleasurable life"), and a life of engagement (e.g., "I am always very absorbed in what I do"). Items were measured on a 5-point likert scale from "very much unlike me" to "very much like me."

Gratitude Questionnaire. Gratitude was measured using the 6-item Gratitude Questionnaire (McCullough, Emmons, \& Tsang, 2002). Items are rated on a 7-point likert scale with "strongly disagree" and "strongly agree" as anchors and exhibit good internal consistency $(\alpha=.82)$. Sample items include "I have so much in life to be thankful for" and "I am grateful to a wide variety of people."

Subjective Happiness Scale. Happiness was measured using the Subjective Happiness Scale (Lyubomirsky \& Lepper, 1999). This is a 4-item measure of global subjective happiness with good internal consistency (alphas ranging from .79 - .94). It includes items such as "In general I consider myself a [not] very happy person" and "Compared to most of my peers, I consider myself more/less happy" rated on a 7-point likert scale with "not a very happy person"//"less happy" and "a very happy person"/"more happy" as anchors.

Mindful Attention Awareness Scale. Mindfulness was measured using Brown and Ryan's (2003) Mindful Attention Awareness Scale. This is a unidimensional 15-item measure with good internal consistency $(\alpha=.82)$. Items are measured on a 6-point likert scale from "strongly disagree" to "strongly agree." Sample items include "I snack without being aware that I'm eating" and "I find myself doing things without paying attention."

Savoring Beliefs Inventory. Savoring was measured using the savouring the moment subscale from the Savoring Beliefs Inventory (Bryant, 2003). This is an 8-item scale with items 
rated on a 7-point likert scale from "strongly agree" to "strongly disagree" with questionable internal consistency (alphas ranging from .68 - .69). Sample items include "I know how to make the most of a good time" and "I feel fully able to appreciate good things."

\section{Results}

Hypotheses 1 and 2 were tested using a repeated-measures multivariate analysis of variance (MANOVA). The independent variable was time and had "pre" and "post" levels. Hypothesis 1 tested changes in measures of well- and ill-being: Psychological Well-being, Subjective Happiness, and Psychological Distress. Hypothesis 2 tested changes in course specific measures: Optimism, Academic Self-efficacy, Approaches to Happiness (Meaning, Pleasure, and Engagement), Gratitude, Mindfulness, and Savoring. Descriptive statistics are presented in Table 1. For univariate tests, Bonferroni corrections were employed to account for multiple comparisons, and after adjustment, $p$ values of .02 and .006 were required for significance for hypotheses 1 and 2 respectively.

Hypothesis 1 evaluated the effects of the course on overall measures of well- and illbeing. Overall, students showed a change on measures of well- and ill-being from pre to post, Wilkes' $\Lambda=.76, F(3,130)=13.96, p<.001$, partial $\eta^{2}=.24$. Univariate tests indicated that psychological well-being increased between time points $\left(F(1,132)=28.57, p<.001, \eta^{2}=.18\right)$ as did Subjective Happiness $\left(F(1,132)=35.93, p<.001\right.$, partial $\left.\eta^{2}=.21\right)$. Psychological Distress decreased between time points $\left(F(1,132)=20.61, p<.001\right.$, partial $\left.\eta^{2}=.14\right)$. These results support hypothesis 1 in that students experienced increased Psychological Well-being and Happiness and decreased Psychological Distress after taking the course.

Hypothesis 2 evaluated the effects of the course on specific measures congruous with course content. Overall, students also showed a change on specific measures from pre to post, 
Wilkes' $\Lambda=.79, F(8,125)=4.28, p<.001$, partial $\eta^{2}=.22$. Univariate tests indicated that students evidenced an increase in optimism between time points $(F(1,132)=28.57, p<.001$, partial $\left.\eta^{2}=.18\right)$ and increased Life of Meaning $\left(F(1,132)=12.54, p=.001\right.$, partial $\left.\eta^{2}=.09\right)$. However, no significant differences were noted in students' levels of Academic Self-efficacy $\left(F(1,132)=5.11, p=.025\right.$, partial $\left.\eta^{2}=.04\right)$, Life of Pleasure $(F(1,132)=0.56, p=.456$, partial $\left.\eta^{2}=0\right)$, Life of Engagement $\left(F(1,132)=3.80, p=.053\right.$, partial $\left.\eta^{2}=.03\right)$, Gratitude $(F(1,132)=$ $3.42, p=.067$, partial $\left.\eta^{2}=.03\right)$, Mindfulness $\left(F(1,132)=0, p=.976\right.$, partial $\left.\eta^{2}=0\right)$, or Savoring $\left(F(1,132)=6.88, p=.01\right.$, partial $\left.\eta^{2}=.05\right)$ before and after taking the course. These results fail to support hypothesis 2 in that students evidenced improvement in only two specific measures (Optimism and Life of Meaning) after taking the course.

\section{Discussion}

Consistent with our primary hypothesis, the Science and Practice of Positive Living (SPOPL) course was effective in improving overall well-being. As a whole, students' scores on facet measures of well-being showed a change from pre to post in the expected direction, but univariate analyses revealed significant changes only in Optimism and Life of Meaning. Due to the large number of positive psychology courses at universities across the country and the growing need for interventions to improve collegiate mental health, these findings carry substantial implications (Parks, 2011; Blanco et al., 2008; Hunt \& Eisenberg, 2010).

\section{Outreach Implications}

While the average level of psychological distress appears to be remaining constant, an increasing number of students are seeking mental health services at college counseling centers (Benton, Robertson, Tseng, Newton, \& Benton, 2003; Center for Collegiate Mental Health [CCMH], 2015). Many counseling centers have responded to students' increased psychological 
distress by increasing outreach efforts and expanding staff (Hunt \& Eisenberg, 2010). Despite these efforts, many centers continue to be overbooked. The results of our study indicate that positive psychology classroom instruction as outreach may be an effective way to promote wellbeing and decrease psychological distress in students. This may be especially true for students displaying a mild to moderate level of distress, similar to the students in our sample.

Positive psychology interventions (PPIs) have been shown to be an effective way to address symptoms of depression, particularly for individuals with preexisting psychological problems and samples that are self-selected (Bolier et al., 2013; Sin \& Lyubomirsky, 2009). We found that students' average improvement in psychological distress as measured by the Outcome Questionnaire (Lambert et al., 1996) in the course of the semester was 7.2 points. A large-scale, naturalistic study found that students' average improvement on the Outcome Questionnaire after a semester of approximately bi-weekly psychotherapy is 10.52 points (Erekson, Lambert, \& Eggett, 2015). Though there are possible differences in initial severity of symptoms, this trend indicates that classroom instruction in positive psychology may be nearly as helpful as individual therapy for some students.

The SPOPL course was housed in the college of student development and was taught by counseling center faculty to students from a variety of majors at various points in their academic careers. Because the sample appears to be adequately representative of the campus community, we believe that transformative positive psychology classes like ours could be considered alongside student development classes such study skills, career strategy, or distress management as a viable means of therapeutic intervention. Further, classroom settings or workshop series provide a much more cost-effective way to provide services to a large number of students compared to psychotherapy (Layne et al., 2008; Jones, 2015). Given the rise in demand for 
counseling services without an accompanying rise in severity of symptoms, positive psychology courses may be an effective way of servicing an influx of treatment seekers and engaging in prevention efforts to curb the rise in demand.

\section{Individual Therapy Implications}

There is ample support for the effectiveness of positive psychology interventions in increasing well-being (Sin \& Lyubomirsky, 2009; Hone et al., 2015). This study adds to the literature by providing support that these findings can be extended into educational settings (Seligman et al., 2009; White \& Waters, 2015). Furthermore, our results support the efficacy of a multifaceted approach to positive psychology interventions (Fordsyce, 1977; Sin \& Lyubomirsky, 2009). In individual therapy, therapists may benefit from incorporating PPIs into the course of their therapy in a manner similar to the course. Over the course of several weeks, therapists could assign as "homework" various PPIs for their clients as a supplement the work done in therapy. Therapists interested in doing so may examine the specific interventions assigned in the course, which are included in Table 2.

\section{Teaching Implications}

With the explosion of positive psychology in undergraduate education, several distinct positive psychology courses have been designed (Kurtz, 2011; Kim-Prieto \& D’Oriano, 2011; Russo-Netzer \& Ben-Shahar, 2011), with many embracing an experiential approach (BiswasDiener \& Patterson, 2011; Jayawickreme \& Forgeard, 2011). An experiential approach has been argued to be effective because it is thought to lead to 1) improved content retention (Kolb \& Kolb, 2005; Kolb, 2014; Van Eynde \& Spencer, 1988), 2) increased well-being and decrease distress, and 3) improved learning given the finding that well-being is linked to a broadening of attention and an increase in creativity (Biswas-Diener \& Patterson, 2011; Rowe et al., 2007; 
Estrada, Isen, \& Young, 1994; Seligman et al., 2009). Although our study did not measure learning outcomes against a control and thus cannot address the first point, the results of our study clearly validate the second point of this approach and partially validate the third point by showing that classroom interventions can be effective in producing increases in well-being outcomes in students.

\section{Limitations and Future Directions}

One possible criticism of our study is that without a control group, it is impossible to be certain that the increases in well-being and happiness and decreases in psychological distress shown in our study were caused by the intervention, as opposed to being caused by a simple maturation effect over the course of the semester. To address this concern, we reviewed studies on well-being and distress in college students. We then identified and isolated studies that contained measures of well-being or distress, contained a control group, and included measurements at the beginning of the semester and within one week of finals. All of the studies we reviewed either indicated a decrease in well-being in the control group from the beginning of the semester to finals week (Ball \& Bax, 2002; Segerstrom, 2001; Travis, et al., 2009), or concluded that there was no significant difference between the two time points (Crandall, Preisler, \& Aussprung, 1992). We were not able to locate any studies that indicated a naturallyoccurring increase in well-being or a decrease in distress during the last two weeks of the semester. Though we cannot rule it out with certainty, we find it unlikely that the significant increases in well-being shown in our study were due to a maturation effect. The fact that students significantly increased in overall happiness but did not significantly increase in specific measures covered in the class (i.e., savoring) seems to indicate that a placebo effect is equally unlikely. 
To our knowledge, our study is the largest sampled evaluation of the psychological outcomes of a positive psychology course. Our study demonstrated substantial effects of the course in improving well-being and decreasing ill-being for students. We encourage future researchers to replicate our study and to extend measurements longitudinally in order to evaluate the lasting impact of this type of intervention. Further, we encourage others to evaluate the efficacy of a positive psychology course relative to waitlist for treatment and active psychotherapy to better understand the role such a course may play in counseling centers.

\section{Conclusion}

We found evidence that a positive psychology course as an outreach and prevention effort was effective in increasing student well-being. We found that the Science and Practice of Positive Living course significantly improved well-being, subjective happiness, and reduced psychological distress among the college students in our sample. This outcome indicates that courses can have positive impacts on collegiate mental health and suggests that positive psychology courses may be a viable resource for colleges and universities to address the increasing demand for clinical services. Our results illuminate the benefits of a multifaceted approach to positive psychology intervention, which involves using a wide variety of interventions that target several different dimensions of happiness (i.e., savoring, mindfulness, gratitude) in order to maximize the increase in overall happiness. We invite continued dialogue about the application of the approaches found in the Science and Practice of Positive Living course. 


\section{References}

Abbott, J., Klein, B., Hamilton, C., \& Rosenthal, A. (2009). The impact of online resilience training for sales managers on wellbeing and performance. E-Journal of Applied Psychology, 5(1), 89-95. doi:10.7790/ejap.v5i1.145

Abedi, M. R., \& Vostanis, P. (2010). Evaluation of quality of life therapy for parents of children with obsessive-compulsive disorders in Iran. European Child \& Adolescent Psychiatry, 19(7), 605-613. doi:10.1007/s00787-010-0098-4

Ball, S., \& Bax, A. (2002). Self-care in medical education: Effectiveness of health-habits interventions for first-year medical students. Academic Medicine, 77(9), 911-917.

Benton, S. A., Robertson, J. M., Tseng, W. C., Newton, F. B., \& Benton, S. L. (2003). Changes in counseling center client problems across 13 years. Professional psychology: Research and practice, 34(1), 66. http://dx.doi.org/10.1037/0735-7028.34.1.66

Biswas-Diener, R., Patterson, L. (2011). An experiential approach to teaching positive psychology to undergraduates. The Journal of Positive Psychology, 6, 477-481. doi: $1080 / 17439760.2011 .634818$

Blanco, C., Okuda, M., Wright, C., Hasin, D. S., Grant, B. F., Liu, S., \& Olfson, M. (2008). Mental health of college students and their non-college-attending peers: Results from the National Epidemiologic Study on Alcohol and Related Conditions. Archives of General Psychiatry,65(12), 1429-1437. doi:10.1001/archpsyc.65.12.1429

Boehm, J. K., Lyubomirsky, S., \& Sheldon, K. M. (2011). A longitudinal experimental study comparing the effectiveness of happiness-enhancing strategies in Anglo Americans and Asian Americans. Cognition And Emotion, 25(7), 1263-1272.

doi:10.1080/02699931.2010.541227 
Bolier, L., Haverman, M., Westerhof, G. J., Riper, H., Smit, F., \& Bohlmeijer, E. (2013). Positive psychology interventions: a meta-analysis of randomized controlled studies. BMC public health, 13(1), 119. doi: 10.1186/1471-2458-13-119

Brown, K.W. \& Ryan, R.M. (2003). The benefits of being present: Mindfulness and its role in psychological well-being. Journal of Personality and Social Psychology, 84, 822-848. doi: $10.1037 / 0022-3514.84 .4 .822$

Bryant, F.B. (2003). Savoring Beliefs Inventory (SBI): A scale for measuring beliefs about savoring. Journal of Mental Health, 12, 175-196. doi: 10.1080/0963823031000103489

Center for Collegiate Mental Health. (2015). Anxiety in college students: 2014 annual report. (Publication No. STA 15-30). Retrieved from http://ccmh.psu.edu/wp-content/ uploads/sites/3058/2015/02/2014-CCMH-Annual-Report.pdf

Crandall, C. S., Preisler, J. J., \& Aussprung, J. (1992). Measuring life event stress in the lives of college students: The undergraduate stress questionnaire (USQ). Journal Of Behavioral Medicine, 15(6), 627-662. doi:10.1007/BF00844860

Emmons, R. A., \& McCullough, M. E. (2003). Counting blessings versus burdens: An experimental investigation of gratitude and subjective well-being in daily life. Journal of Personality And Social Psychology, 84(2), 377-389. doi:10.1037/0022-3514.84.2.377

Erekson, D. M., Lambert, M. J., \& Eggett, D. L. (2015). The relationship between session frequency and psychotherapy outcome in a naturalistic setting. Journal of Consulting and Clinical Psychology, 83, 1097-1107. doi: http://dx.doi.org/10.1037/a0039774

Estrada, C. A., Isen, A. M., \& Young, M. J. (1994). Positive affect improves creative problem solving and influences reported source of practice satisfaction in physicians. Motivation and emotion, 18(4), 285-299. 
Feicht, T., Wittmann, M., Jose, G., Mock, A., von Hirschhausen, E., \& Esch, T. (2013).

Evaluation of a seven-week web-based happiness training to improve psychological wellbeing, reduce stress, and enhance mindfulness and flourishing: A randomized controlled occupational health study. Evidence-Based Complementary and Alternative Medicine, 2013. http://dx.doi.org/10.1155/2013/676953

Fordyce, M. W. (1977). Development of a program to increase personal happiness. Journal of Counseling Psychology, 24(6), 511-521. doi:10.1037/0022-0167.24.6.511

Fordyce, M. W. (1983). A program to increase happiness: Further studies. Journal of Counseling Psychology, 30(4), 483-498. doi:10.1037/0022-0167.30.4.483

Gall, T. L., Evans, D. R., \& Bellerose, S. (2000). Transition to first-year university: Patterns of change in adjustment across life domains and time. Journal of Social And Clinical Psychology, 19(4), 544-567. doi:10.1521/jscp.2000.19.4.544

Goodmon, L. B., Middleditch, A. M., Childs, B., \& Pietrasiuk, S. E. (2016). Positive psychology course and its relationship to well-being, depression, and stress. Teaching of Psychology, 43, 232-237. doi: 10.1177/0098628316649482

Grossman, P., Niemann, L., Schmidt, S., \& Walach, H. (2004). Mindfulness-based stress reduction and health benefits: A meta-analysis. Journal of Psychosomatic Research, 57(1), 35-43. doi:10.1016/S0022-3999(03)00573-7

Hone, L. C., Jarden, A., \& Schofield, G. M. (2015). An evaluation of positive psychology intervention effectiveness trials using the re-aim framework: A practice-friendly review. The Journal of Positive Psychology, 10(4), 303-322. doi:10.1080/17439760.2014.965267 
Hunt, J., \& Eisenberg, D. (2010). Mental health problems and help-seeking behavior among college students. Journal of Adolescent Health, 46(1), 3-10. doi:10.1016/j.jadohealth.2009.08.008

Hurley, D. B., \& Kwon, P. (2012). Results of a study to increase savoring the moment: Differential impact on positive and negative outcomes. Journal of Happiness Studies, 13(4), 579-588. doi:10.1007/s10902-011-9280-8

Huynh, K. H., Hall, B., Hurst, M. A., \& Bikos, L. H. (2015). Evaluation of the positive re-entry in corrections program: A positive psychology intervention with prison inmates. International Journal of Offender Therapy And Comparative Criminology, 59(9), 10061023. doi:10.1177/0306624X14523385

Jayawickreme, E., \& Forgeard, M. J. C. (2011). Insight or data: Using non-scientific sources to teach positive psychology. The Journal of Positive Psychology, 6, 499-505. doi: $10.1080 / 17439760.2011 .634819$

Jones, P. J, (2015). Applying Counseling Theory to Pedagogy. National Career Development Association Convergence Journal.

Judd, L. L., Akiskal, H. S., \& Paulus, M. P. (1997). The role and clinical significance of subsyndromal depressive symptoms (SSD) in unipolar major depressive disorder. Journal of Affective Disorders, 45(1-2), 5-17. doi:10.1016/S0165-0327(97)00055-4

Kolb, A. Y., \& Kolb, D. A. (2005). Learning styles and learning spaces: Enhancing experiential learning in higher education. Academy of Management Learning \& Education, 4(2), 193 212.

Kolb, D. A. (2014). Experiential learning: Experience as the source of learning and development. Upper Saddle River, NJ: FT press. 
Klibert, J., Lamis, D. A., Collins, W., Smalley, K. B., Warren, J. C., Yancey, C. T., \& Winterowd, C. (2014). Resilience mediates the relations between perfectionism and college student distress. Journal of Counseling \& Development, 92(1), 75-82. doi:10.1002/j.1556-6676.2014.00132.x

Kim-Prieto, C., \& D’Oriano, C. (2011). Integrating research training and the teaching of positive psychology. The Journal of Positive Psychology, 6, 457-462. doi:

$10.1080 / 17439760.2011 .634827$

Kurtz, J. L. (2011). Happiness and self-knowledge: A positive psychology and judgment and decision-making hybrid course. The Journal of Positive Psychology, 6, 463-467. doi: $10.1080 / 17439760.2011 .634820$

Lambert, M. J., Burlingame, G. M., Umphress, V., Hansen, N. B., Vermeersch, D. A., Clouse, G. C., \& Yanchar, S. C. (1996). The reliability and validity of the outcome questionnaire. Clinical Psychology and Psychotherapy, 3(4), 249-258.

Layne, C. M., Saltzman, W. R., Poppleton, L., Burlingame, G. M., Pašalić, A., Duraković, E., ... \& Steinberg, A. M. (2008). Effectiveness of a school-based group psychotherapy program for war-exposed adolescents: a randomized controlled trial. Journal of the American Academy of Child \& Adolescent Psychiatry, 47(9), 1048-1062. doi:10.1097/CHI.0b013e31817eecae

Linley, P. A., Joseph, S., Harrington, S., \& Wood, A. M. (2006). Positive psychology: Past, present, and (possible) future. The Journal of Positive Psychology, 1(1), 3-16. doi:10.1080/17439760500372796

Lyubomirsky, S., \& Lepper, H. S. (1999). A measure of subjective happiness: Preliminary reliability and construct validation. Social Indicators Research, 46, 137-155. 
Maybury, K. K. (2013). The influence of a positive psychology course on student well-being. Teaching Of Psychology, 40(1), 62-65. doi:10.1177/0098628312465868

McCullough, M. E., Emmons, R. A., \& Tsang, J. (2002). The grateful disposition: A conceptual and empirical topography. Journal of Personality and Social Psychology, 82, 112-127. doi: 10.1037//0022-3514.82.1.112

Milem, J. F., \& Berger, J. B. (1997). A modified model of college student persistence: Exploring the relationship between Astin's theory of involvement and Tinto's theory of student departure. Journal of College Student Development, 38(4), 387-400.

Ouweneel, E., Le Blanc, P. M., \& Schaufeli, W. B. (2013). On being grateful and kind: Results of two randomized controlled trials on study-related emotions and academic engagement. The Journal of Psychology: Interdisciplinary And Applied, 148(1), 37-60. doi:10.1080/00223980.2012.742854

Parks, A. C. (2011). The state of positive psychology in higher education: Introduction to the special issue. The Journal of Positive Psychology, 6, 429-431. doi: $10.1080 / 17439760.2011 .637729$

Parks, A. C., \& Szanto, R. K. (2013). Assessing the efficacy and effectiveness of a positive psychology-based self-help book. Terapia Psicológica, 31(1), 141-149. doi:10.4067/S0718-48082013000100013

Peterson, C., Park, N., \& Seligman, M.E.P. (2005). Orientations to happiness and life satisfaction: The full life versus the empty life. Journal of Happiness Studies, 6, 25-41. doi: $10.1007 / \mathrm{s} 10902-004-1278-\mathrm{Z}$ 
Pittman, L. D., \& Richmond, A. (2008). University belonging, friendship quality, and psychological adjustment during the transition to college. Journal of Experimental Education, 76(4), 343-361. doi:10.3200/JEXE.76.4.343-362

Reed, G. L., \& Enright, R. D. (2006). The effects of forgiveness therapy on depression, anxiety, and posttraumatic stress for women after spousal emotional abuse. Journal of Consulting and Clinical Psychology, 74(5), 920-929. doi:10.1037/0022-006X.74.5.920

Rowe, G., Hirsh, J. B., Anderson, A. K., \& Smith, E. E. (2007). Positive affect increases the breadth of attentional selection. PNAS Proceedings of The National Academy of Sciences of The United States of America, 104(1), 383-388. doi:10.1073/pnas.0605198104

Russo-Netzer, P., \& Ben-Shahar, T. (2011). 'Learning from success': A close look at a popular positive psychology course. The Journal of Positive Psychology, 6, 468-476. doi: $10.1080 / 17439760.2011 .634823$

Ryff, C.D. (1995). Psychological well-being in adult life. Current Directions in Psychological Science, 4, 99-104. doi: 10.1111/1467-8721.ep10772395

Ryff, C.D., \& Keyes, C.L.M. (1995). The structure of psychological well-being revisited. Journal of Personality and Social Psychology, 69, 719-727. doi: 10.1037/00223514.69.4.719

Samuolis, J., \& Griffin, K. W. (2014). Identity distress and negative affect in college students. Identity: An International Journal of Theory and Research, 14(4), 246-254. doi:10.1080/15283488.2014.944694

Scheier, M. F., Carver, C. S., \& Bridges, M. W. (1994). Distinguishing optimism from neuroticism (and trait anxiety, self-mastery, and self-esteem): A reevaluation of the life 
orientation test. Journal of Personality and Social Psychology, 67, 1063-1078. doi:10.1037//0022-3514.67.6.1063

Segerstrom, S. C. (2001). Optimism, goal conflict, and stressor-related immune change. Journal Of Behavioral Medicine, 24(5), 441-467. doi:10.1023/A:1012271410485

Seligman, M. P., Rashid, T., \& Parks, A. C. (2006). Positive psychotherapy. American Psychologist, 61(8), 774-788. doi:10.1037/0003-066X.61.8.774

Seligman, M. E., Schulman, P., DeRubeis, R. J., \& Hollon, S. D. (1999). The prevention of depression and anxiety. Prevention \& Treatment, 2(1), 8a.

Seligman, M. P., Schulman, P., \& Tryon, A. M. (2007). Group prevention of depression and anxiety symptoms. Behaviour Research And Therapy, 45(6), 1111-1126. doi:10.1016/j.brat.2006.09.010

Sin, N. L., \& Lyubomirsky, S. (2009). Enhancing well-being and alleviating depressive symptoms with positive psychology interventions: A practice-friendly meta-analysis. Journal of Clinical Psychology, 65(5), 467-487. doi:10.1002/jclp.20593

Smith, S. A. (1988). A comparison of structured small-group instruction and conventional instruction in an academic skills class (Unpublished doctoral dissertation). University of Minnesota-Twin Cities, St. Paul.

Travis, F., Haaga, D. F., Hagelin, J., Tanner, M., Nidich, S., Gaylord-King, C., \& ... Schneider, R. H. (2009). Effects of transcendental meditation practice on brain functioning and stress reactivity in college students. International Journal Of Psychophysiology, 71(2), 170-176. doi:10.1016/j.ijpsycho.2008.09.007 
Van Eynde, D. F., \& Spencer, R. W. (1988). Lecture versus experiential learning: Their differential effects on long-term memory. Journal of Management Education, 12(4), 5258. doi:10.1177/105256298801200404

White, M. A., \& Waters, L. E. (2015). A case study of 'The good school:' Examples of the use of Peterson's strengths-based approach with students. The Journal of Positive Psychology, 10(1), 69-76. doi:10.1080/17439760.2014.920408 
Tables and Figures

Table 1. Descriptive Statistics.

\begin{tabular}{lccccc}
\hline \multicolumn{1}{c}{ Scale Name } & $\begin{array}{c}\text { Highest } \\
\text { Scale } \\
\text { Rating }\end{array}$ & \multicolumn{2}{c}{ Pre } & \multicolumn{2}{c}{ Post } \\
\hline Psychological Well Being & \multicolumn{1}{c}{ Mean } & SD & Mean & SD \\
Life Orientation Test & 5 & 4.45 & 0.62 & 4.66 & 0.61 \\
Outcome Questionnaire & 3 & 7.50 & 0.80 & 3.80 & 0.73 \\
Self in School & 7 & 5.68 & 0.97 & 5.82 & 0.83 \\
Approaches to Happiness & & & & & \\
$\quad$ Meaning & 5 & 3.72 & 0.73 & 3.88 & 0.70 \\
$\quad$ Pleasure & 5 & 3.08 & 0.73 & 3.12 & 0.82 \\
$\quad$ Engagement & 5 & 2.79 & 0.56 & 2.88 & 0.52 \\
Gratitude Questionnaire & 7 & 6.25 & 0.82 & 6.35 & 0.68 \\
Subjective Happiness Scale & 7 & 4.93 & 1.38 & 5.38 & 1.21 \\
Mindful Attention Awareness Scale & 6 & 3.75 & 0.71 & 3.76 & 0.79 \\
Savoring Beliefs Inventory & 7 & 4.82 & 1.29 & 5.04 & 1.16 \\
\hline
\end{tabular}

Note: All values reported are average rating with the exception of the OQ, which is reported as the total scale value for ease of comparison with other studies 
Table 2. Experiential Intervention Assignments

Module Intervention Description

\begin{tabular}{|c|c|c|}
\hline Happiness I & $\begin{array}{l}\text { Informal } \\
\text { Survey }\end{array}$ & $\begin{array}{l}\text { Informally talk to at least } 4 \text { people in your life (friends, } \\
\text { roommates, parents, etc.). Ask them about how they define } \\
\text { happiness, what makes them happy, etc. }\end{array}$ \\
\hline Happiness II & $\begin{array}{l}\text { Three Good } \\
\text { Things }\end{array}$ & $\begin{array}{l}\text { Every night, for } 1 \text { week, write down and reflect about } 3 \\
\text { things that went well for you during that day. }\end{array}$ \\
\hline \multirow[t]{2}{*}{$\begin{array}{l}\text { Interpersonal } \\
\text { Relationships }\end{array}$} & $\begin{array}{l}\text { Opening } \\
\text { Yourself to } \\
\text { Connection }\end{array}$ & $\begin{array}{l}\text { During one week, push yourself to open up to others, more } \\
\text { than is typical for you. Take risks and move beyond your } \\
\text { comfort zone. }\end{array}$ \\
\hline & $\begin{array}{l}\text { Active- } \\
\text { Constructive } \\
\text { Responding }\end{array}$ & $\begin{array}{l}\text { During one week, practice the skill of Active-Constructive } \\
\text { Responding in your conversations by responding } \\
\text { enthusiastically and expressing interest in others. }\end{array}$ \\
\hline \multirow[t]{2}{*}{ Gratitude I } & Daily Naikan & $\begin{array}{l}\text { During at least } 3 \text { days during this week, practice naikan by } \\
\text { making a list of what you have received, what you have } \\
\text { given, and how you were a source of inconvenience or } \\
\text { difficulty to others. }\end{array}$ \\
\hline & $\begin{array}{l}\text { Increasing } \\
\text { your Scope of } \\
\text { Awareness }\end{array}$ & $\begin{array}{l}\text { For } 1 \text { week, keep a running of list of things that you are } \\
\text { grateful for that you may have taken for granted before. }\end{array}$ \\
\hline Gratitude II & $\begin{array}{l}\text { Gratitude } \\
\text { Letter }\end{array}$ & $\begin{array}{l}\text { Write a letter to someone in your life that has significantly } \\
\text { contributed to you in some way. Read your letter aloud to } \\
\text { that person. }\end{array}$ \\
\hline $\begin{array}{l}\text { Character } \\
\text { Strengths }\end{array}$ & $\begin{array}{l}\text { Using your } \\
\text { Strengths in } \\
\text { New Ways }\end{array}$ & $\begin{array}{l}\text { Of your top } 5 \text { VIA strengths, select } 1 \text {. Over the next week, } \\
\text { practice your strength at least } 3 \text { times. Focus on activities } \\
\text { that are new and different but still utilize your strength. }\end{array}$ \\
\hline \multirow[t]{2}{*}{$\begin{array}{l}\text { Distress } \\
\text { Management }\end{array}$} & $\begin{array}{l}\text { Reclaiming } \\
\text { Control of } \\
\text { your Life }\end{array}$ & $\begin{array}{l}\text { First, create a list of distressing things in your life. Next, } \\
\text { create an "If/Then" list using these items ("If } \\
\text { a problem for me, then I would __" weren't } \\
\text { activities on your "Then" list. }\end{array}$ \\
\hline & $\begin{array}{l}\text { Expressive } \\
\text { Writing } \\
\text { Exercise }\end{array}$ & $\begin{array}{l}\text { During three days during one week, for } 10-15 \text { minutes each } \\
\text { day, write about your distress: fears, feelings of failure, } \\
\text { worries, frustrations, etc. }\end{array}$ \\
\hline
\end{tabular}


Practice Stress From a given list of effective coping strategies, pick one Management that is new to you. During one week, apply this strategy to stressors in your life and record your observations.

Purposes \& $\quad$ Write Your How would you like your friends and family to remember Values Legacy you? Imagining the final moments of your life, write your legacy the way you would want it to be.

Exploring During one day this week, reflect on the purposes of your Values \& behaviors, as well as your values. Frequently question Purposes yourself "What is my purpose in doing this now?" Record your thoughts.

Decision $\quad$ Assess your $\quad$ Write and reflect upon your decision making style in 1) Making Decision past decisions you have made 2) decisions you might be Making Style currently facing 3) upcoming decisions you might encounter

Mindfulness Observing During one week, perform mindfulness meditation on at your Mind least 3-4 days, for 5-10 minutes each session.

Savoring Luxuriating During one week, practice savoring at least 5 times by focusing on a good experience and reflecting on it.

Mini-Vacation During the next week, take a mini-vacation at least twice by allocating 20 minutes from your day to do an activity you find enjoyable. Do not multitask during this time.

Exercising Will Exercising Pick one activity that is difficult for you. Do the activity your Will every day during one week, at the time you planned to do it.

Note: For modules with more than one intervention, students were instructed to choose and complete one intervention. 